\title{
Risk of Spreading Soft Rot Through Cutting Dips Against Whiteflies in Greenhouse-Grown Poinsettia
}

\author{
Rosemarije Buitenhuis, ${ }^{\dagger}$ Anissa Poleatewich, Mark Jandricic, and Michael Brownbridge \\ Vineland Research and Innovation Centre, Vineland Station, ON, LOR 2E0, Canada
}

\begin{abstract}
Dipping is a quick and cost-effective technique to reduce pest infestations on unrooted cuttings of greenhouse ornamental crops. Large numbers of cuttings are immersed in an insecticidal treatment, e.g., biopesticides and/or insecticidal soap, before they are stuck in the growing medium and rooted. This research investigated the risk of cross-contamination of poinsettia cuttings with Pectobacterium carotovorum subsp. carotovorum, a potentially devastating pathogen causing soft rot, through the dipping process. Sampling at four commercial greenhouses showed that $P$. carotovorum subsp. carotovorum was present in all dip suspensions during and after processing poinsettia cuttings; concentrations up to $1 \times 10^{5} \mathrm{CFU} / \mathrm{ml}$ were detected. A laboratory experiment determined that $P$. carotovorum subsp. carotovorum-infected cuttings could contaminate clean dip suspensions to

dip suspensions artificially inoculated with $P$. carotovorum subsp. carotovorum (from $1 \times 10^{3}$ to $1 \times 10^{7} \mathrm{CFU} / \mathrm{ml}$ ). Disease incidence increased as $P$. carotovorum subsp. carotovorum concentrations in the dip suspension increased and the variety 'Prestige Red' was more susceptible than 'Freedom White.' However, even at the highest $P$. carotovorum subsp. carotovorum concentration of $1 \times 10^{7} \mathrm{CFU} / \mathrm{ml}$, the proportion of diseased cuttings was low at $6 \%$ for var. 'Freedom White,' but higher at $21 \%$ for var. 'Prestige Red.' We conclude that $P$. carotovorum subsp. carotovorum transfer among unrooted poinsettia cuttings through the dipping process is relatively low although some varieties are sensitive to high levels of inoculum. Even so, strict sanitation practices are still important to prevent build-up of inoculum in the dip treatment.
\end{abstract} similar levels. These results indicated that there is potential for disease transfer during dipping. The potential for cross-contamination of healthy cuttings was evaluated by immersing poinsettia cuttings in
Keywords: Pectobacterium carotovorum subsp. carotovorum, Bemisia tabaci, biopesticides, poinsettia, Beauveria bassiana, insecticidal soap
Starting a crop with clean plant material is one of the most important factors in integrated pest and disease management (Lewis et al. 1997). For floriculture crops started from vegetative cuttings, rigorous "clean stock programs" ensure that selected true-to-type plants are free from pathogens (i.e., bacteria, fungi, or viruses) before they are advanced to the next stock plant production stages (Faust et al. 2017). To further comply with phytosanitary requirements, especially since unrooted cuttings are shipped worldwide and cross international borders, stock plants at the propagative facility are often heavily treated with pesticides.

Despite propagators' best efforts, small numbers of insects or mites are frequently present on cuttings received by growers. In particular, the whitefly Bemisia tabaci (Gennadius) (Hemiptera: Aleyrodidae) is regularly found on poinsettia (Euphorbia pulcherrima Willd. ex Klotsch) cuttings (Cuthbertson et al. 2011; Frewin et al.

Current address of A. Poleatewich: University of New Hampshire, Durham, NH 03824, U.S.A.

Current address of M. Brownbridge: Bioworks Inc., Victor, NY 14564, U.S.A.

${ }^{\dagger}$ Corresponding author: R. Buitenhuis;

Rose.Buitenhuis@vinelandresearch.com

Funding: Thanks to Dümmen Orange, BioWorks Inc., Koppert Canada, Westbrook Greenhouses, Schenck Farms, Colonial Florists, Linwell Gardens, Flowers Canada Growers for financial and material support. This project was funded in part by Agriculture and Agri-Food Canada through Growing Forward 2 (GF2), a federal-provincial-territorial initiative. The Agricultural Adaptation Council assists in the delivery of GF2 in Ontario.

The author(s) declare no conflict of interest

Accepted for publication 09 March 2020.

(c) 2020 Her Majesty The Queen in Right of Canada as represented by the Minister of Agriculture and Agri-Food
2014). Starting a crop with infested plant material can create major challenges; pest populations can quickly grow to levels that cannot be controlled using preventative biological methods. In addition, these pests have already been exposed to numerous chemistries at the propagator, so the effectiveness of pesticide treatments is likely to be compromised by the development of pesticide resistance (Frewin et al. 2014).

In response to this issue, new whitefly management programs have been developed for floriculture crops such as poinsettia, including early mitigation strategies using cutting dips. Dipping (immersing cuttings completely in a liquid) is a quick and cost-effective method of treating unrooted cuttings before they are stuck in the growing medium (Aristizábal et al. 2018; Buitenhuis et al. 2016; Buxton and Clarke 1994; Osborne 1986). This method of treatment provides excellent leaf coverage, something that is much more difficult to achieve using conventional spray techniques once the cuttings are placed in the misting range (Osborne 1986), unless materials with translaminar activity are used (Krauter et al. 2017). By dipping pest-infested cuttings in reduced-risk products, such as mineral oil, insecticidal soap, and biopesticides, rather than traditional synthetic pesticides, there is less risk to operators, and the potential for resistance development is lower as these products have multiple modes of action (Najar-Rodríguez et al. 2008; Weinzierl 2000). Reduced-risk products also leave minimal residues and are highly compatible with natural enemies, allowing biological control to be used immediately thereafter (Brownbridge and Buitenhuis 2019; Lacey et al. 2015).

Previous research (Buitenhuis et al. 2016) demonstrated that immersion of infested poinsettia cuttings in mineral oil $(0.1 \% \mathrm{v} / \mathrm{v})$ or a combination treatment of insecticidal soap $(0.5 \%)+$ Beauveria bassiana (BotaniGard 22WP, $1.25 \mathrm{~g} /$ liter) killed $69 \%$ and $71 \%$, respectively, of B. tabaci immature stages on the leaves. Effects on population growth were still evident 8 weeks later. Phytotoxicity risks of these treatments to poinsettia were acceptable, and treatment residues had little effect on survival of whitefly parasitoids (Encarsia formosa, Eretmocerus mundus), making the dips highly compatible with biological control. In fact, greenhouse trials showed that a combined treatment of dips followed by releases of parasitoids provided 
the best control of B. tabaci in the developing crop, and this sequential combination was significantly better than a parasitoids-only treatment (R. Buitenhuis, personal observation).

One potential risk of poinsettia cutting dip treatments is the transfer and spread of plant pathogens, such as the highly infectious Pectobacterium carotovorum (syn. Erwinia carotovora) (Jones) Holland, which causes soft rot diseases on many plant species including ornamentals (Charkowski 2018; Ma et al. 2007). Soft rot of poinsettia caused by $P$. carotovorum subsp. carotovorum is characterized by the development chlorotic spots anywhere along the stem and purplish-black petioles, followed by shriveling of the petioles and wilting of the affected leaves, leaving the infected tissues soft and water-soaked (Daughtrey and Chase 2016). The onset of symptoms is rapid and once they develop, cuttings usually die (Benson et al. 2002). This disease is particularly prevalent under warm conditions (Charkowski 2006; Smadja et al. 2004), which coincides with the time of year (June to August) when poinsettia crops are started in the Northern hemisphere. Stress, for example from shipping the cuttings across continents, also makes plants more susceptible (Ramegowda and Senthil-Kumar 2015). Cutting failure due to $P$. carotovorum subsp. carotovorum infection in poinsettia can be very high, and losses up to $40 \%$ are not uncommon in Canada and the U.S.A. (M. Daughtrey, personal communication). This pathogen is ubiquitous in the environment and can cause latent infections. It is normally dispersed through soil, water (e.g., irrigation water, hydroponic solutions, rain, or splashing), or through contact with infected plants. Infected plant material may serve as a source of active bacteria for several weeks. Bacteria invade the healthy plant tissue through wounds, cracks, and natural openings (Charkowski 2006, 2018; Perombelon and Kelman 1980). In the case of cutting dips, the risk of pathogen spread may be increased as thousands of cuttings are consecutively immersed in the same dip treatment. If one or several cuttings in a batch are infected with $P$. carotovorum subsp. carotovorum, these could serve as a source of inoculum in the dip treatment and the pathogen could potentially spread to healthy cuttings. Little is known, however, about the level of risk posed by the dipping process and if increasing bacterial concentration results in higher disease incidence.

The objective of this research, therefore, was to evaluate the risk of disease transfer through dip treatments of poinsettia cuttings. Samples were taken from dip treatments at commercial greenhouses to determine the natural prevalence of $P$. carotovorum subsp. carotovorum. The degree to which dip treatments were contaminated by $P$. carotovorum subsp. carotovorum-infected cuttings was also determined. Finally, the risk of cross-contamination from infected to healthy cuttings was evaluated by dipping unrooted poinsettia cuttings in suspensions that were artificially inoculated with $P$. carotovorum subsp. carotovorum. To determine whether different poinsettia varieties were more susceptible to infection through the dipping process than others, a known susceptible ('Prestige Red') and a less susceptible variety ('Freedom White') were included in the evaluation.

\section{Materials and Methods}

$P$. carotovorum subsp. carotovorum isolate. A strain of $P$. carotovorum subsp. carotovorum was isolated from a dip suspension that had been used to treat poinsettia cuttings at a commercial greenhouse. To satisfy Koch's postulates, pathogenicity of the isolate was confirmed by infecting healthy poinsettia cuttings using a stab inoculation technique. The bacterium was reisolated from symptomatic cuttings and identified as $P$. carotovorum subsp. carotovorum by $16 \mathrm{~S} / 18 \mathrm{~S}$ rRNA analysis at the University of Guelph diagnostic laboratory. The isolate was stored at $-80^{\circ} \mathrm{C}$ until use in the experiments. Both an optical density standard curve and a growth curve were determined to facilitate preparation of $P$. carotovorum subsp. carotovorum suspensions for the experiments.

Survey of $P$. carotovorum subsp. carotovorum contamination in commercial dip suspensions. To determine the prevalence of $P$. carotovorum subsp. carotovorum as a contaminant in commercial greenhouse dip suspensions, samples were collected from four local greenhouses (Niagara region, $\mathrm{ON}$, Canada; referred to here as greenhouses A, B, C, and D). All greenhouses dipped their cuttings in insecticidal soap $+B$. bassiana. Samples were collected from source water and from dipping tanks before, during (every hour), and after workers dipped the poinsettia cuttings. At each time point, the dip suspension was agitated by stirring and two $5-\mathrm{ml}$ samples were pipetted into sterile 15-ml Falcon centrifuge tubes. Samples were kept on ice for transport to the laboratory. Dips were sampled at greenhouse $\mathrm{A}, \mathrm{B}$, and $\mathrm{C}$ for two consecutive weeks, and only one time at greenhouse D. For each dipping week, 2,000 cuttings that had been dipped in the sampled tanks and an equal number of non-dipped cuttings were observed for 14 weeks after sticking and monitored for soft rot symptoms. The number of infected cuttings per bench was recorded accordingly.

The concentration of (putative) P. carotovorum subsp. carotovorum in the dip suspensions collected from commercial greenhouses was estimated by preparing serial dilutions from each 5-ml sample in sterile deionized water. Fifty microliters of each dilution was plated onto modified Miller-Schroth medium (MMS) and incubated at $28^{\circ} \mathrm{C}$. MMS is semiselective for both Pectobacterium and Dickeya species of bacteria (Miller and Schroth 1972; Pierce and McCain 1992). Colonies of Pectobacterium and Dickeya species growing on this medium form pink-red-orange cavities, whereas growth of other bacteria is either suppressed or fail to produce cavities. After $24 \mathrm{~h}$, the number of colonies on each plate was counted and the concentration per $\mathrm{ml}$ of dip suspension was calculated. The remainder of all samples from greenhouses B, C, and D were also sent to the University of Guelph diagnostic laboratory for DNA multiscan analysis (De Ceuster Corporation of St. Katelijne-Waver, Belgium), a PCR test that screens samples for 30 common waterborne plant pathogens. Results of this multiscan are semiquantitative, giving a score from "not detected," to "low," "moderate," and "high."

$P$. carotovorum subsp. carotovorum contamination of dip suspensions from infected cuttings. A laboratory experiment was conducted to determine the level of $P$. carotovorum subsp. carotovorum contamination that could occur from infected cuttings. $P$. carotovorum subsp. carotovorum was cultured in LB broth at $28^{\circ} \mathrm{C}$ for $14 \mathrm{~h}$ and then used to prepare a stock suspension containing $1 \times 10^{8}$ $\mathrm{CFU} / \mathrm{ml}\left(\mathrm{OD}_{600}=0.055\right)$. One hundred poinsettia cuttings (var. 'Prestige Red') were stab-inoculated with $10 \mu \mathrm{l}$ of $P$. carotovorum subsp. carotovorum suspension containing $1 \times 10^{8} \mathrm{CFU} / \mathrm{ml}$ by piercing the stem of each cutting at the base of the third or fourth leaf using a sterile $200-\mu l$ pipette tip. The tip was left in place until the inoculum was completely absorbed $(\sim 24 \mathrm{~h})$. Cuttings were then stuck in Oasis Wedgestrips (OASIS Grower Solutions, Smithers-Oasis North America, Kent, OH, U.S.A.) and placed in a misting greenhouse $\left(25^{\circ} \mathrm{C} ; 100 \% \mathrm{RH}\right.$; mist $5 \mathrm{~s}$ every $\left.5 \mathrm{~min}\right)$. After $48 \mathrm{~h}, 10$ cuttings displaying early symptoms of $P$. carotovorum subsp. carotovorum infection (discolored vascular system originating from the infection site) were removed from the misting room. Each infected cutting was placed individually into a beaker containing $500 \mathrm{ml}$ of sterile deionized water and agitated for $30 \mathrm{~s}$. The concentration of $P$. carotovorum subsp. carotovorum in the water was estimated by plating as described above for the greenhouse survey.

Disease transfer in spiked dip suspensions. This experiment was conducted to determine if poinsettia cuttings dipped in a $P$. carotovorum subsp. carotovorum-contaminated dip tank could become infected and manifest soft rot symptoms. A second objective was to determine the effect of $P$. carotovorum subsp. carotovorum concentration on infection rates. The experiment was set up following a factorial design with two poinsettia varieties and two dip suspensions (water ['W'] or insecticidal soap + B. bassiana ['SB']) inoculated with seven pathogen concentrations ( 0 [water only; control], $10^{3}$, $10^{4}, 10^{5}, 10^{6}, 10^{7} \mathrm{CFU} / \mathrm{ml}$ ). For each variety, a positive (stabinoculated ['SI']) and a negative (nondipped ['ND']) control were included. The experimental unit consisted of a group of 20 poinsettia cuttings, and there were three replicates per treatment per trial (= block). The trials were repeated four times between January and June 2016, for a total of 12 replicates per treatment. 
For each replicated experiment, unrooted poinsettia cuttings of two varieties ('Prestige Red' and 'Freedom White') were obtained from Dümmen Orange (Columbus, OH, U.S.A.), a commercial propagator. Cuttings were held overnight in their packaging in a cooler at $15^{\circ} \mathrm{C}$ and used the next day in the experiment.

The nondipped, negative control cuttings were planted first, before any of the dipped treatments, to minimize any risk of $P$. carotovorum subsp. carotovorum contamination. Stab-inoculated cuttings, which served as a positive control, were inoculated with $10 \mu \mathrm{l}$ of $P$. carotovorum subsp. carotovorum at a concentration of $1 \times 10^{8} \mathrm{CFU} / \mathrm{ml}$ as described above.

Two dip suspensions were prepared. The first consisted of sterile deionized water ('W') and the second was a combination of insecticidal soap + B. bassiana strain GHA ('SB'). The combination treatment was prepared in sterile deionized water using $0.5 \%$ v/v Bug B Gon (potassium salts of fatty acids $47 \%$, Scotts EcoSense; Scotts Canada Ltd., Mississauga, ON, Canada) mixed with 1.25 g/liter BotaniGard 22WP (active ingredient B. bassiana GHA strain, BioWorks Inc., Victor, NY, U.S.A.).

$P$. carotovorum subsp. carotovorum was cultured as described above in LB broth. Flasks were placed on a shaker (VWR Incubating Orbital Shaker, Model 5000I at $28^{\circ} \mathrm{C}$ and $150 \mathrm{rpm}$ ) for $14 \mathrm{~h}$, and then used to prepare a stock suspension containing $1 \times 10^{8} \mathrm{CFU} / \mathrm{ml}$ $\left(\mathrm{OD}_{600}=0.055\right)$. Five dilutions from $1 \times 10^{3}$ to $1 \times 10^{7} \mathrm{CFU} / \mathrm{ml}$ and a control (no-P. carotovorum subsp. carotovorum) were prepared in 4 liters of dip suspension (sterile deionized water or insecticidal soap $+B$. bassiana). This range was based on results from the previous experiment, which determined background levels of $P$. carotovorum subsp. carotovorum in greenhouse dip samples, where bacterial concentrations up to $1 \times 10^{5} \mathrm{CFU} / \mathrm{ml}$ were detected.

Groups of 20 poinsettia cuttings each were immersed in the respective treatment suspension and agitated for $30 \mathrm{~s}$. Samples were collected from each dip treatment before and after the cuttings were immersed, and serial dilutions were plated onto MMS media to confirm P. carotovorum subsp. carotovorum presence and determine the concentration.

After treatment, the stem ends of all cuttings were coated with rooting hormone (Stim-Root \# 2, Master Plant Prod Inc., Brampton, ON, Canada) and the cuttings were stuck into Oasis Wedge strips, 10 cuttings per strip. Each group of 20 cuttings were then randomly placed in a mist greenhouse $\left(25^{\circ} \mathrm{C}, 100 \% \mathrm{RH}\right.$, mist $5 \mathrm{~s}$ every $10 \mathrm{~min}$ ). Each group had its own mist emitter and the groups were spaced $140 \mathrm{~cm}$ apart to prevent any cross-contamination by splashing. Cuttings were monitored daily for 10 days for the development of disease symptoms after dipping and the percentage of diseased cuttings was calculated per group of 20 cuttings.

Effect of dip suspension on $P$. carotovorum subsp. carotovorum viability. An experiment was conducted to determine whether the dip suspension affected $P$. carotovorum subsp. carotovorum viability. A time series was established to compare the viability of $P$. carotovorum subsp. carotovorum in two suspensions (sterile deionized water or insecticidal soap $+B$. bassiana) over time. $P$. carotovorum subsp. carotovorum from the stored culture was cultured in $\mathrm{LB}$ broth at $28^{\circ} \mathrm{C}$ for $14 \mathrm{~h}$ and then used to prepare a stock suspension containing $1 \times 10^{8} \mathrm{CFU} / \mathrm{ml}\left(\mathrm{OD}_{600}=0.055\right)$. Four replicates of $500-\mathrm{ml}$ Erlenmeyer flasks were prepared for each treatment, each containing
$150 \mathrm{ml}$ of water or insecticidal soap $+B$. bassiana suspension. Each was inoculated with $150 \mu \mathrm{l}$ of the stock suspension to obtain a final concentration of $1.0 \times 10^{5} \mathrm{CFU} / \mathrm{ml}$. All flasks were placed on a rotary shaker at $28^{\circ} \mathrm{C}$ and $150 \mathrm{rpm}$. At time $0,0.5,1,2$, and $4 \mathrm{~h}$ after inoculation, a 5-ml sample was taken from each flask and serial dilutions were plated onto MMS medium and incubated at $28^{\circ} \mathrm{C}$. After $24 \mathrm{~h}$, the CFU on each plate were counted. Using counts from time 0 as the initial concentration for comparison, the change in concentration of viable $P$. carotovorum subsp. carotovorum cells was calculated for each time point for each flask. At the end of the experiment, the $\mathrm{pH}$ of the test suspensions in each flask were determined with a $\mathrm{pH}$ meter.

Statistical analysis. The plate counts used to determine concentrations of $P$. carotovorum subsp. carotovorum before and after dipping in the water and insecticidal soap $+B$. bassiana treatments were log transformed. The transformed data were analyzed using a 3-way ANOVA, with time (pre-dip vs-post-dip), dip suspension, and serial dilutions as independent variables, using proc GLM.

The data on percent diseased cuttings 9 days after treatment were analyzed with GLIMMIX using a binomial model in a generalized randomized block design with trial (block) as a random effect. Factors were variety (Prestige Red and Freedom White) and a combination variable of dip treatment and $P$. carotovorum subsp. carotovorum concentration ('Dip and $P$. carotovorum subsp. carotovorum treatment': ND, SI, W-0, W-10 3 , W-10 ${ }^{4}, \mathrm{~W}-10^{5}, \mathrm{~W}-10^{6}, \mathrm{~W}-10^{7}$, SB$\left.0, \mathrm{SB}-10^{3}, \mathrm{SB}-10^{4}, \mathrm{SB}-10^{5}, \mathrm{SB}-10^{6}, \mathrm{SB}-10^{7}\right)$. This combination variable was created to obtain a balanced design. No disease was observed in any of the cuttings dipped in $1 \times 10^{3} \mathrm{CFU} / \mathrm{ml} P$. carotovorum subsp. carotovorum suspensions. To ensure convergence of the model, these data $\left(\mathrm{W}-10^{3}\right.$ and $\left.\mathrm{SB}-10^{3}\right)$ were excluded from the analysis. Multiple comparisons among treatments were done using contrasts.

To analyze effects of the dip suspension composition on $P$. carotovorum subsp. carotovorum viability, change in population size (CFU counts) with respect to the initial population size (time $=0$ ) was analyzed using repeated measures ANOVA using proc GLM.

All data were analyzed using SAS.

\section{Results}

Level of $P$. carotovorum subsp. carotovorum contamination in dip suspensions (commercial greenhouse survey and laboratory trial). $P$. carotovorum subsp. carotovorum was not detected in the dip source water sampled at four commercial greenhouses (Table 1). Furthermore, no plant pathogens were detected in the source water using the DNA multiscan analysis. Using selective media, $P$. carotovorum subsp. carotovorum was detected at up to $4.3 \times 10^{4} \mathrm{CFU} / \mathrm{ml}$ in four of the seven dip suspensions sampled (all greenhouses) before any cuttings were dipped, suggesting that the dipping tanks were contaminated. DNA multiscan results also indicated the presence of Fusarium spp. in the tank suspensions before cuttings were dipped. During dipping (at $1 \mathrm{~h}$ ) and post dipping, average $P$. carotovorum subsp. carotovorum levels increased, up to $1.6 \times 10^{5} \mathrm{CFU} / \mathrm{ml}$ (Table 1), and other pathogens such as Fusarium sp., Pythium sp., and Botrytis cinerea were detected at "low" levels using the multiscan technique. Note that $P$. carotovorum subsp. carotovorum in this experiment is a putative identification, based on its

Table 1. Putative Pectobacterium carotovorum subsp. carotovorum concentrations (CFU/ml) in source water and dip suspensions before, during, and after dipping poinsettia cuttings at four commercial greenhouses (A, B, C, and D). Samples plated on modified Miller-Schroth (MMS) medium and incubated at $28^{\circ} \mathrm{C}$ for $24 \mathrm{~h}$. Each number is the average of two samples; n/a indicates no samples were taken.

\begin{tabular}{lccccc}
\hline Greenhouse & Sampling week & Source water & Predip & During dip (1 h) & Postdip \\
\hline A & 1 & 0 & $4.5 \times 10^{1}$ & $4.9 \times 10^{4}$ & $1.5 \times 10^{5}$ \\
& 2 & 0 & 0 & $7.0 \times 10^{2}$ & $\mathrm{n} / \mathrm{a}$ \\
B & 1 & 0 & 0 & $2.1 \times 10^{4}$ & $8.7 \times 10^{2}$ \\
& 2 & 0 & $3.5 \times 10^{1}$ & $1.4 \times 10^{5}$ & $0.5 \times 10^{1}$ \\
C & 1 & 0 & $4.3 \times 10^{4}$ & $1.6 \times 10^{5}$ \\
& 2 & 0 & 0 & $1.2 \times 10^{4}$ & $\mathrm{n} / \mathrm{a}$ \\
D & 1 & 0 & $6.1 \times 10^{3}$ & $\mathrm{n} / \mathrm{a}$ & $\mathrm{n} / \mathrm{a}$ \\
\hline
\end{tabular}


growth characteristics (orange cavities) on MMS selective media and past disease diagnosis records in these greenhouses.

Despite the presence of pathogens in the dip suspensions sampled, no disease symptoms were observed on the dipped (and nondipped) cuttings during follow-up visits to the four commercial greenhouses.

$P$. carotovorum subsp. carotovorum contamination from infected cuttings. In the laboratory experiment, clean water became contaminated with $P$. carotovorum subsp. carotovorum after immersion of stab-inoculated cuttings. Although $P$. carotovorum subsp. carotovorum levels were extremely variable (mean concentration $1.04 \times 10^{5} \pm 5.62 \times 10^{4} \mathrm{CFU} / \mathrm{ml}$ ), results did indicate that infected cuttings could contaminate a dip suspension.

Disease transfer in spiked dip suspensions. Samples taken from all treatments before dipping any cuttings confirmed that $P$. carotovorum subsp. carotovorum concentrations in both water and insecticidal soap $+B$. bassiana treatments were within the expected range. There was a significant interaction between sampling time (prevspost dip) and $P$. carotovorum subsp. carotovorum concentration $\left(\mathrm{F}_{5,36}=60.62, P<0.0001\right)$. When comparing pre- and postdip concentrations of $P$. carotovorum subsp. carotovorum, there was no significant difference among treatments except for the lowest $P$. carotovorum subsp. carotovorum concentration $\left(10^{3}\right)$ and the no- $P$. carotovorum subsp. carotovorum control. In these treatments, $P$. carotovorum subsp. carotovorum concentration in postdip samples was higher than in predip samples, indicating that dipping cuttings may have added (putative) $P$. carotovorum subsp. carotovorum to the dip suspensions (Fig. 1). Postdip assessments of these two treatments confirmed that each contained around $10^{4} \mathrm{CFU} / \mathrm{ml}$.

Almost all stab-inoculated cuttings in the positive control developed disease symptoms by 9 days after treatment, confirming the infectivity of the $P$. carotovorum subsp. carotovorum strain used in the experiment (Fig. 2). A small percentage of nondipped cuttings in the negative control developed disease symptoms, indicating that some of the cuttings arrived from the propagator were infected with $P$. carotovorum subsp. carotovorum or similar soft rot-causing bacteria. Similarly, a proportion of the cuttings dipped in "water only" treatment developed soft-rot symptoms and the level of infection was not significantly different from that observed in cuttings dipped in $P$. carotovorum subsp. carotovorum suspensions containing $10^{4}$ and $10^{5} \mathrm{CFU} / \mathrm{ml}$ (Fig. 2).

In general, disease incidence was significantly higher on 'Prestige Red' compared with 'Freedom White' (Fig. 2). There were also significant differences in disease incidence among cuttings for the combination variable 'Dip and $P$. carotovorum subsp. carotovorum treatment.' Within this variable, contrasts showed that

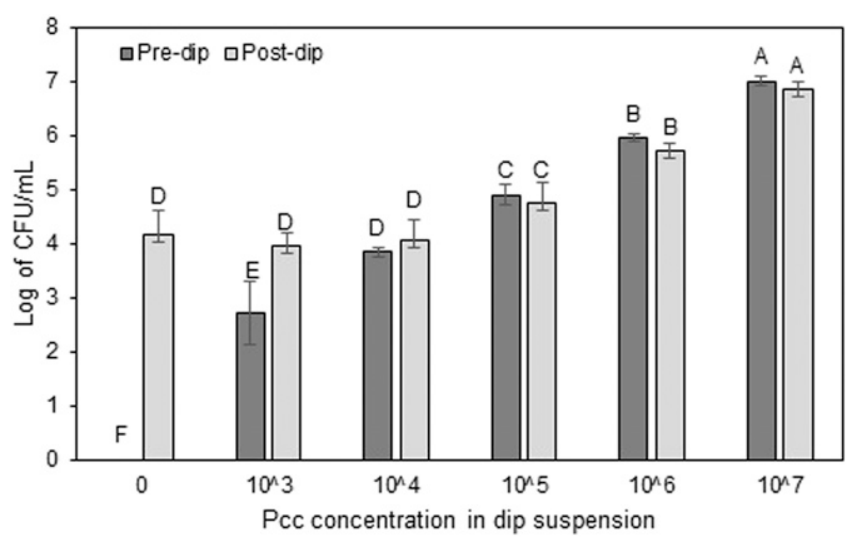

Fig. 1. Mean ( \pm SE) Pectobacterium carotovorum subsp. carotovorum concentrations (CFU/ml) in dip suspensions before and after dipping of poinsettia cuttings. $P$. carotovorum subsp. carotovorum concentrations in the suspensions ranged from $10^{3}$ to $10^{7} \mathrm{CFU} / \mathrm{ml}$, and a non-P. carotovorum subsp. carotovorum control (0) was also included $(n=4)$. Different letters above the bars indicate significant differences between pre- and postdip concentrations of $P$. carotovorum subsp. carotovorum within a treatment $(\alpha=0.05)$. there was no effect of dip suspension (water versus insecticidal soap $+B$. bassiana) on disease incidence. However, there were significant differences among $P$. carotovorum subsp. carotovorum treatments $(P$. carotovorum subsp. carotovorum concentrations $0,10^{4}$ to $10^{7}$, nondipped and stab inoculated), where disease incidence increased to an average of $6 \%$ (var. Freedom White) and $21 \%$ (var. Prestige Red) at the highest $P$. carotovorum subsp. carotovorum concentration tested, and disease incidence was significantly higher in the stab inoculated cuttings than all other treatments. No interactions were observed for any of the variables (Table 2).

Effect of dip suspension on $P$. carotovorum subsp. carotovorum viability. There was evidence of a slight effect of insecticidal soap $+B$. bassiana on $P$. carotovorum subsp. carotovorum viability, but not of water (Fig. 3) (treatment $\mathrm{F}_{1,24}=8.02, P=0.0299$; time $\mathrm{F}_{4,24}=3.27, P=0.0284$; interaction $\left.\mathrm{F}_{4,24}=6.53, P=0.0011\right)$. After 4 h, viable $P$. carotovorum subsp. carotovorum counts were $29 \%$ lower than the initial counts in the insecticidal soap $+B$. bassiana treatment. In the water treatment, $P$. carotovorum subsp. carotovorum counts were unchanged after $4 \mathrm{~h}$. The difference may have been caused by the high $\mathrm{pH}$ of insecticidal soap $+B$. bassiana suspensions (10.7) as compared with the water treatment (6.8).

\section{Discussion}

Dip treatments are often carried out to reduce pest levels on unrooted cuttings of ornamental plants such as poinsettia. However, there are concerns that this practice could have unintended negative effects and increase disease risks as a result of pathogen transfer from infected to healthy cuttings through the dip suspension. Dipping of unrooted cuttings is similar to postharvest processing of leafy greens, which involves washing leaf material with water in flumes or tanks where large amounts of produce are processed at the same time. The transfer of human pathogens, such as Escherichia coli, Salmonella sp., or Listeria sp., from contaminated leaves to wash water and to subsequent processing batches of leafy greens has been reported (Gombas et al. 2017). Soft rot-causing bacteria, such as Pectobacterium spp., are known to cause high crop losses, and one of their main dispersal mechanisms is through contaminated water (Charkowski 2006, 2018; Perombelon and Kelman 1980). However, the research presented here demonstrated that, despite the presence of soft rot bacteria in a dipping suspension, pathogen transfer and subsequent disease development in healthy poinsettia cuttings was generally low $(0 \%$ in the commercial trial and 6 to $21 \%$ in the laboratory trial at the highest $P$. carotovorum subsp. carotovorum concentration tested).

Table 2. ANOVA table for disease incidence in poinsettia cuttings of two different varieties ('Prestige Red,' 'Freedom White'), 9 days after dipping in Pectobacterium carotovorum subsp. carotovorum spiked suspensions. $P$. carotovorum subsp. carotovorum concentrations in the suspensions ranged from $10^{3}$ to $10^{7} \mathrm{CFU} / \mathrm{ml}$, and a non-P. carotovorum subsp. carotovorum control (0), nondipped and stab-inoculated cuttings were also included in the trial Effects of subfactors were estimated using contrasts.

\begin{tabular}{|c|c|c|c|}
\hline Factor & DF & F-value & $P$ value \\
\hline Variety & 1 & 12.16 & 0.0009 \\
\hline $\begin{array}{l}\text { Dip and } P \text {. carotovorum subsp. carotovorum } \\
\text { treatment }\end{array}$ & 11 & 17.69 & $<0.0001$ \\
\hline Dip suspension & 1 & 0.59 & 0.4454 \\
\hline $\begin{array}{l}\text { P. carotovorum subsp. carotovorum } \\
\text { concentration }\end{array}$ & 6 & 32.30 & $<0.0001$ \\
\hline $\begin{array}{l}\text { Dip treatment } \times P \text {. carotovorum subsp. } \\
\text { carotovorum concentration }\end{array}$ & 4 & 1.03 & 0.397 \\
\hline $\begin{array}{l}\text { Variety } \times \text { dip and } P \text {. carotovorum subsp. } \\
\text { carotovorum treatment }\end{array}$ & 11 & 0.48 & $0.90^{\top}$ \\
\hline Variety $\times$ dip suspension & 1 & 0.73 & 0.3947 \\
\hline $\begin{array}{l}\text { Variety } \times P \text {. carotovorum subsp. } \\
\text { carotovorum concentration }\end{array}$ & 6 & 0.68 & 0.662 \\
\hline $\begin{array}{l}\text { Variety } \times \text { dip suspension } \times P \text {. carotovorum } \\
\text { subsp. carotovorum concentration }\end{array}$ & 4 & 0.19 & 0.94 \\
\hline
\end{tabular}


Sampling at commercial greenhouses confirmed that $P$. carotovorum subsp. carotovorum (or Erwinia spp. that grow on the MMS selective medium) was present in all dip suspensions during and after processing poinsettia cuttings, at levels up to $10^{5} \mathrm{CFU} / \mathrm{ml}$. The same was observed in the spiked dip experiment, where postdip samples of the control treatments contained (putative) $P$. carotovorum subsp. carotovorum up to $10^{4} \mathrm{CFU} / \mathrm{ml}$. At the commercial greenhouses, several samples of the dip suspensions that were taken before any cuttings were treated were already contaminated with pathogens, including (putative) P. carotovorum subsp. carotovorum. These pathogens may have been left over from previous dip treatments or may have been present in the greenhouse environment. A laboratory experiment determined that $P$. carotovorum subsp. carotovoruminfected cuttings could contaminate clean dip suspensions to similar levels as those observed in the commercial greenhouse samples, confirming that infected cuttings can be a source of $P$. carotovorum subsp. carotovorum contamination.

Overall, these results indicate that there is potential for disease transfer. However, without knowing the conditions and the pathogen concentration in the dip suspension at which healthy cuttings become infected, the risk level could not be determined. To address this, several factors were considered in the $P$. carotovorum subsp. carotovorum-spiked dip experiment: dip suspension composition, poinsettia variety, and $P$. carotovorum subsp. carotovorum concentration.

The composition of the dip suspension can potentially affect the accumulation of pathogens in the dip treatment and/or their viability or infectivity. Insecticidal soap may act as a surfactant, washing bacteria off the surface of cuttings and facilitating their transfer into the dip suspension. This effect was not observed here, as the concentration of $P$. carotovorum subsp. carotovorum in the insecticidal soap + $B$. bassiana preparation was no higher than that detected in the water treatment. On the contrary, insecticidal soap $+B$. bassiana appeared to have a slight suppressive effect on $P$. carotovorum subsp. carotovorum levels, as observed in the $P$. carotovorum subsp. carotovorum viability experiment, especially after $4 \mathrm{~h}$. No significant decrease in $P$. carotovorum subsp. carotovorum viability was observed in the spiked dip experiment comparing pre- and postdip colony counts. However, all cutting dips were completed within an hour of the treatment preparation, so we did not anticipate a decline in $P$. carotovorum subsp. carotovorum levels inside this timeframe. A suppressive effect of insecticidal soap on fungal pathogens has been observed before (Chase and Osborne 1983), but no information is available on the effect of potassium salts of fatty acids on bacterial pathogens. Unfortunately, the reduction in viability is not sufficient, or fast enough, to prevent accumulation of pathogens in the dip suspension and ultimately is unlikely to eliminate the risk of disease transmission. This was confirmed in the spiked dip experiment where there were no differences in the disease incidence between water and insecticidal soap $+B$. bassiana treatments.

Overall, disease levels were consistently higher in treated 'Prestige Red' cuttings than 'Freedom White.' This may reflect varietal differences in susceptibility to $P$. carotovorum subsp. carotovorum infection through dipping or could have been a result of low levels of $P$. carotovorum subsp. carotovorum infection in the incoming cuttings. Despite not being exposed to $P$. carotovorum subsp. carotovorum, a small percentage of nondipped cuttings (negative control) and cuttings dipped in clean water still developed soft rot symptoms, especially in 'Prestige Red.' It is unlikely that these results were caused by contamination from other treatments as good sanitary practices were used throughout, including processing treatments without $P$. carotovorum subsp. carotovorum first and maintaining a distance between treatments in the greenhouse to prevent dispersal of $P$. carotovorum subsp. carotovorum inoculum by splashing. It is possible that some of the cuttings arrived with a systemic bacterial infection. Pectobacterium (= Erwinia) spp. are able to survive asymptomatically for long periods as latent infections, colonizing the vascular system of ornamentals; little is known about how the plant responds to these latent

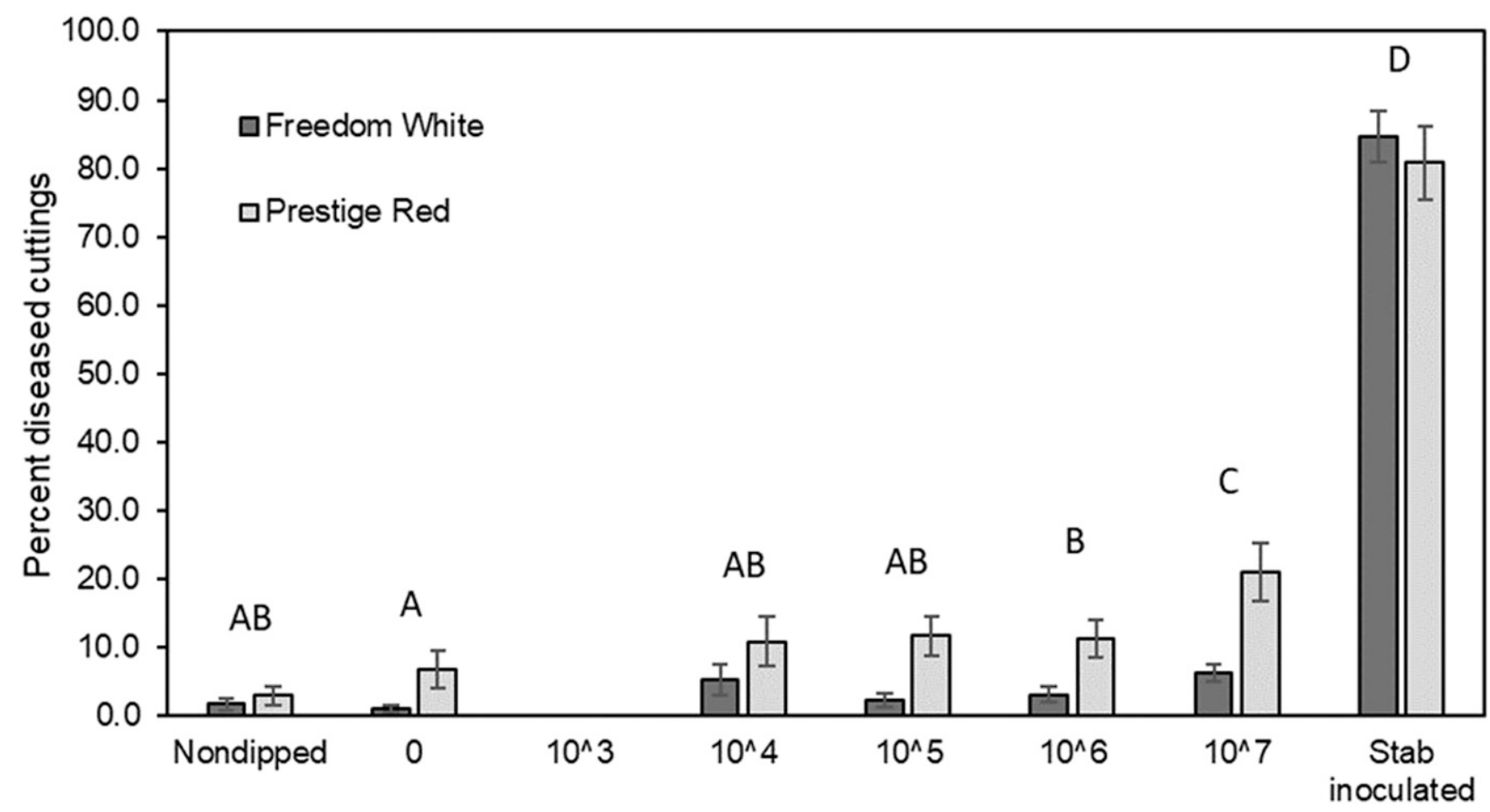

Fig. 2. Mean ( \pm SE) percent diseased poinsettia cuttings of two different varieties ('Prestige Red,' 'Freedom White'), 9 days after dipping in Pectobacterium carotovorum subsp. carotovorum spiked suspensions. P. carotovorum subsp. carotovorum concentrations in the suspensions ranged from $10^{3}$ to $10^{7} \mathrm{CFU} / \mathrm{ml}$, and a non-P. carotovorum subsp. carotovorum control ( 0 ) was included. For comparison, nondipped and stab-inoculated cuttings were also included in the trial. The experimental unit consisted of a group of 20 poinsettia cuttings. The experiment was repeated four times between January and June 2016, for a total of 12 replicates per treatment. Different letters above grouped bars indicate significant differences among $P$. carotovorum subsp. carotovorum treatments $(\alpha=0.05)$. Disease responses between the two varieties were significantly different, but no interactions were observed. 


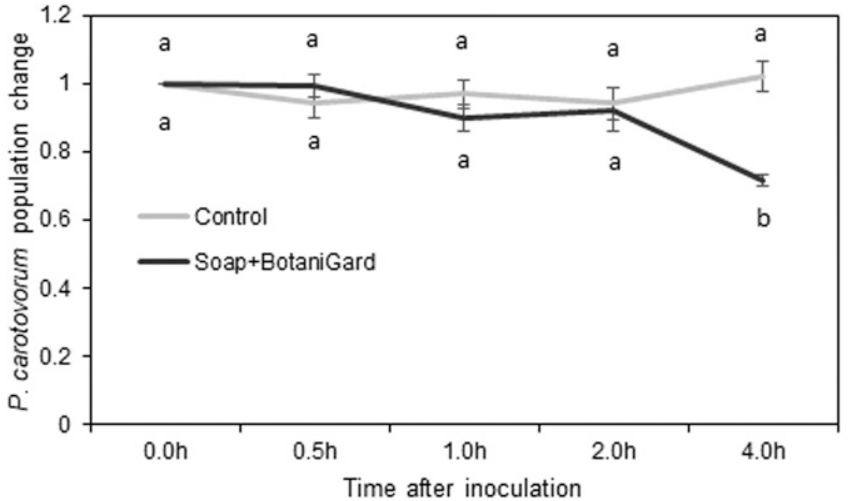

Fig. 3. Effect of dip suspension composition on the mean concentration ( $\pm \mathrm{SE})$ of viable Pectobacterium carotovorum subsp. carotovorum cells over time $(n=4)$. Data are presented as change in population size with respect to the initial population size at time $=0$. Different letters indicate significant differences among treatments and time points $(\alpha=0.05)$.

infections (Charkowski 2006). This can be devastating for vegetatively propagated crops since the pathogen is easily spread during propagation and, once inside the vascular system of a plant, there are no practical large-scale methods to eliminate the pathogen and cure the plant (Charkowski 2006).

In the spiked dip experiment, the expected pattern of a dosemortality response was observed: increasing disease incidence with increasing $P$. carotovorum subsp. carotovorum concentration in the dip. However, even at the highest $P$. carotovorum subsp. carotovorum concentration $\left(1 \times 10^{7} \mathrm{CFU} / \mathrm{ml}\right)$, the proportion of diseased cuttings was low in 'Freedom White' $(6 \%)$ but higher in 'Prestige Red' ( $21 \%$ ), a $P$. carotovorum subsp. carotovorum susceptible variety. These infection rates are consistent with those in commercial poinsettia production when cuttings are not dipped (R. Buitenhuis, unpublished data).

$P$. carotovorum subsp. carotovorum pathogenesis uses a celldensity-dependent communication system known as quorum sensing (Faure and Dessaux 2007). As a result, if populations are too low, symptoms do not develop. This may explain, in part, why disease was not observed in the commercial trials, and low disease incidence was found in the laboratory trial, even though $P$. carotovorum subsp. carotovorum was present.

Putting it all together, the risk of disease transfer can be inferred: The first laboratory experiment demonstrated that $P$. carotovorum subsp. carotovorum can contaminate the dip suspension from (artificially) infected cuttings. One infected cutting in $500 \mathrm{ml}$ of water resulted in a concentration of $1 \times 10^{5} \mathrm{CFU} / \mathrm{ml}$. To obtain infective levels, as determined in the spiked dip experiment (i.e., $1 \times 10^{5}$ to $\left.1 \times 10^{7} \mathrm{CFU} / \mathrm{ml}\right), 80$ to 8,000 infected cuttings should go through the dip (assuming a dip volume of 40 liters). As workers briefly inspect each cutting before sticking it in the growing media, we assume that such a high number of infected cuttings would be detected and appropriate measures be taken. We conclude that the risk of disease transfer is very low. This corresponds with experiences from growers over the past three years, who have been using either water dips to rehydrate cuttings, and/or insecticidal soap $+B$. bassiana dips to control whiteflies (R. Buitenhuis, unpublished data).

However, cuttings that are stressed or do not look healthy should not be dipped, as this state could increase their susceptibility to pathogens, including $P$. carotovorum subsp. carotovorum. This recommendation is based on observations in the spiked dip experiment which was performed over the course of 6 months. Treatments in the first two blocks were made to cuttings that were shipped in January to March, which is outside the normal poinsettia season. Although the effect of block (i.e., time of year) was not statistically significant $(P=0.064)$, these cuttings seemed more susceptible to disease than cuttings treated in the last two blocks, which were produced 'in-season,' i.e., for shipment from June to July.

Finally, detection of Pectobacterium/Erwinia spp. in the dipping suspension at commercial greenhouses, before any cuttings were processed, emphasizes that good sanitation practices are important, and that equipment and the surrounding areas have to be cleaned properly and sterilized before and after use. In addition, more susceptible cultivars could be dipped last, or in a separate tank, as they are more likely to contaminate the dipping suspension.

As research continues into the utility of dips for management of other pests (e.g., thrips and spider mites) and on other crops, the risk of transfer of other pathogens such as Dickeya chrysanthemi, Xanthomonas hortorum pv. pelargonii, or Ralstonia solanacearum should be investigated. Future research should also determine ways in which pathogen transfer risks can be mitigated, e.g., through the use of biofungicides combined with sanitation practices (the frequency with which dip suspensions are changed) to prevent the potential build-up of inoculum to infectious levels.

\section{Acknowledgments}

We thank Taro Saito, Rebecca Eerkes, Michelangelo La Spina, Ashley Summerfield, Wonhyo Lee, Matthew Goertz, Darlene Nesbitt, and Irina PerezValdez for technical assistance.

\section{Literature Cited}

Aristizábal, L. F., Avery, P. B., Kumar, V., Caldwell, J. H., McKenzie, C. L., and Osborne, L. S. 2018. Mitigating trans-boundary movement of Bemisia tabaci (Hemiptera: Aleyrodidae) on Mentha sp. by pre-shipping treatments of biopesticides. Crop Prot. 107:71-78.

Benson, M. D., Hall, J. L., Moorman, G. W., Daughtry, M. L., Chase, A. R., and Lamour, K. H. 2002. The history and diseases of poinsettia, the Christmas flower. Plant Health Prog. https://doi.org/10.1094/PHP-2002-0212-01-RV.

Brownbridge, M., and Buitenhuis, R. 2019. Integration of microbial biopesticides in greenhouse floriculture: The Canadian experience. J. Invertebr. Pathol. 165:4-12.

Buitenhuis, R., Brownbridge, M., Brommit, A., Saito, T., and Murphy, G. 2016. How to start with a clean crop: Biopesticide dips reduce populations of Bemisia tabaci (Hemiptera: Aleyrodidae) on greenhouse poinsettia propagative cuttings. Insects 7:48.

Buxton, J., and Clarke, A. 1994. Evaluation of insecticide dips to control Bemisia tabaci on poinsettia cuttings. Pestic. Sci. 42:141-142.

Charkowski, A. O. 2006. The soft rot Erwinia. Pages 423-505 in: Plant-Associated Bacteria. S. S. Gnanamanickam, ed. Springer,Utrecht, The Netherlands.

Charkowski, A. O. 2018. The changing face of bacterial soft-rot diseases. Annu. Rev. Phytopathol. 56:269-288.

Chase, A. R., and Osborne, L. S. 1983. Influence of an insecticidal soap on several foliar diseases of foliage plants. Plant Dis. 67:1021-1023.

Cuthbertson, A. G. S., Blackburn, L. F., Eyre, D. P., Cannon, R. J. C., Miller, J., and Northing, P. 2011. Bemisia tabaci: The current situation in the UK and the prospect of developing strategies for eradication using entomopathogens. Insect Sci. 18:1-10.

Daughtrey, M. L., and Chase, A. R. 2016. Diseases of poinsettia. Pages 1-51 in: Handbook of Florist's Crops Diseases. R. J. McGovern and W. H. Elmer, eds. Springer, Cham, Switzerland.

Faure, D., and Dessaux, Y. 2007. Quorum sensing as a target for developing control strategies for the plant pathogen Pectobacterium. Eur. J. Plant Pathol. 119:353-365.

Faust, J. E., Dole, J. M., and Lopez, R. G. 2017. Cutting industry. Pages 121-172 in: Horticultural Reviews. J. Janick, ed. Wiley-Blackwell, Hoboken, NJ.

Frewin, A. J., Scott-Dupree, C., Murphy, G., and Hanner, R. 2014. Demographic trends in mixed Bemisia tabaci (Hemiptera: Aleyrodidae) cryptic species populations in commercial poinsettia under biological control- and insecticide-based management. J. Econ. Entomol. 107:1150-1155.

Gombas, D., Luo, Y., Brennan, J., Shergill, G., Petran, R., Walsh, R., Hau, H., Khurana, K., Zomorodi, B., Rosen, J., Varley, R., and Deng, K. 2017. Guidelines to validate control of cross-contamination during washing of fresh-cut leafy vegetables. J. Food Prot. 80:312-330.

Krauter, P. C., Heinz, K. M., and Arthurs, S. 2017. Protecting unrooted cuttings from Bemisia tabaci (Hemiptera Aleyrodidae) during propagation. J. Insect Sci. 17:2055-2064.

Lacey, L. A., Grzywacz, D., Shapiro-Ilan, D. I., Frutos, R., Brownbridge, M., and Goettel, M. S. 2015. Insect pathogens as biological control agents: Back to the future. J. Invertebr. Pathol. 132:1-41.

Lewis, W. J., van Lenteren, J. C., Phatak, S. C., and Tumlinson, J. H. 1997. A total system approach to sustainable pest management. Proc. Natl. Acad. Sci. USA 94:12243-12248.

Ma, B., Hibbing, M. E., Kim, H.-S., Reedy, R. M., Yedidia, I., Breuer, J., Glasner, J. D., Perna, N. T., Kelman, A., and Charkowski, A. O. 2007. Host range and 
molecular phylogenies of the soft rot enterobacterial genera Pectobacterium and Dickeya. Phytopathology 97:1150-1163.

Miller, T. D., and Schroth, M. N. 1972. Monitoring the epiphytic populations of Erwinia amylovora on pear with a selective medium. Phytopathology 62:1175-1182.

Najar-Rodríguez, A. J., Lavidis, N. A., Mensah, R. K., Choy, P. T., and Walter, G. H. 2008. The toxicological effects of petroleum spray oils on insects Evidence for an alternative mode of action and possible new control options. Food Chem. Toxicol. 46:3003-3014.

Osborne, L. S. 1986. Dip treatment of tropical ornamental foliage cuttings in Fluvalinate to prevent spread of insect and mite infestations. J. Econ. Entomol. 79:465-470.

Perombelon, M. C. M., and Kelman, A. 1980. Ecology of the soft rot Erwinias. Annu. Rev. Phytopathol. 18:361-387.
Pierce, L., and McCain, A. H. 1992. Selective medium for isolation of pectolytic Erwinia sp. Plant Dis. 76:382-384.

Ramegowda, V., and Senthil-Kumar, M. 2015. The interactive effects of simultaneous biotic and abiotic stresses on plants: Mechanistic understanding from drought and pathogen combination. J. Plant Physiol. 176:47-54.

Smadja, B., Latour, X., Trigui, S., Burini, J. F., Chevalier, S., and Orange, N. 2004 Thermodependence of growth and enzymatic activities implicated in pathogenicity of two Erwinia carotovora subspecies (Pectobacterium spp.) Can. J. Microbiol. 50:19-27.

Weinzierl, R. A. 2000. Botanical insecticides, soaps, and oils. Pages 101-122 in: Biological and Biotechnical Control of Insect Pests. J. E. Rechcigl and N. A Rechcigl, eds. CRC Press LLC, Boca Raton, FL. 